\title{
AS TRAJETÓRIAS DOS AGRICULTORES FAMILIARES NAS ATIVIDADES DE PROCESSAMENTO DE ALIMENTOS NO RIO GRANDE DO SUL: UMA TIPOLOGIA DA EVOLUÇÃO
}

\author{
TRAJECTORIES OF FAMILY FARMERS IN FOOD \\ PROCESSING ACTIVITIES IN RIO GRANDE DO SUL: A \\ TYPOLOGY OF THEIR EVOLUTION
}

\author{
Chaiane Leal Agne \\ Universidade Estadual do Rio Grande do Sul - Cachoeira do Sul - RS - Brasil \\ Paulo Dabdab Waquil \\ Universidade Federal do Rio Grande do Sul - Porto Alegre - RS - Brasil
}

\begin{abstract}
Resumo: As atividades de processamento de alimentos emergiram como temáticas importantes dentro da área do Desenvolvimento Rural, especialmente em meados da década de 1990. Ao considerar a história, percebe-se que essas atividades evoluíram ao longo do tempo. Os agricultores adotaram novas práticas e novos processos, influenciados por um conjunto de conhecimentos e saberes técnicos. O presente artigo tem como objetivo apresentar uma proposta de uma tipologia para caracterizar a trajetória das atividades de processamento de alimentos, utilizando como contexto empírico a realidade de quatro regiões gaúchas. Foram entrevistadas 64 famílias (agricultores familiares) que processam alimentos, utilizando um formulário semiestruturado, observações e diários de campo para coletar os dados. Para análise dos dados, foi utilizada a técnica qualitativa denominada análise de conteúdo, que guiou a construção das tipologias. Foram identificados quatro grupos distintos de famílias, que retratam a diversidade de suas trajetórias nessas atividades. As principais diferenças entre os grupos referem-se: aos objetivos das famílias, à forma como iniciaram e modificaram a produção e ao emprego de conhecimentos técnicos. A tipologia permite ampliar o conhecimento sobre o "universo" diverso que caracteriza essas atividades no Rio Grande do Sul, contribuindo para a reflexão sobre as intervenções preconizadas pelos programas e políticas públicas para a agricultura familiar.
\end{abstract}

Palavras-chave: Agricultura familiar. Atividades de Processamento de Alimentos. Trajetória. Tipologia.

\begin{abstract}
The food processing activities have emerged as important issues within the Rural Development area, especially in the mid-1990s. When considering the history, these activities have evolved over time. Farmers have adopted new practices and processes influenced by a set of knowledge and technical skills. This article aims to present a proposal for a typology to characterize the trajectory of food processing activities, using as empirical context reality four regions of Rio Grande do Sul, Brazil. 64 families were interviewed (family farmers) who process food, using a semi-structured form, observations and field diaries to collect data. For data analysis, we used the qualitative technique called content analysis that guided the construction of typologies. Four distinct groups of families were identified, which depict the diversity of their trajectories. The main differences between the groups is relate to: the objectives of the families, the way started and changed the production, by using technical knowledge. The typology allows greater knowledge about the "universe" diversity that characterizes these activities in Rio Grande do Sul, contributing to the reflection on the interventions advocated by the programs and policies for family farming.

Keywords: Family farmers. Food processing activities. Trajectory. Typology.
\end{abstract}




\section{Introdução}

As atividades de processamento de alimentos emergiram como temáticas importantes dentro da área do Desenvolvimento Rural, especialmente em meados da década de 1990. No que se refere ao debate acadêmico, as principais questões estavam alicerçadas sobre a oportunidade de construir alternativas produtivoeconômicas para a agricultura familiar.

Tais discussões influenciaram no redirecionamento de programas e políticas públicas para a agricultura familiar, uma vez que o Estado passou a considerar as atividades de processamento de alimentos como uma das principais linhas do Programa Nacional de Fortalecimento para a Agricultura Familiar - PRONAF, construído em 1996. No que tange aos efeitos do acesso ao crédito por parte das chamadas "Agroindústrias Rurais Familiares", tais recursos oportunizaram aos agricultores o investimento nas suas estruturas físicas, tais como a compra de equipamentos e máquinas.

As últimas políticas e programas construídos, tais como: o Programa Nacional de Alimentação Escolar - PNAE e o Programa de Agroindústria Familiar PAF oportunizaram a criação de canais de comercialização e a oferta de suporte técnico às famílias, especialmente nas etapas de fabricação desses alimentos.

Apesar desses avanços, a obtenção de registros sanitários ainda configurase como a principal dificuldade para os agricultores, especialmente familiares (AGNE, 2010, GUIMARÃES, 2011, GAZOLLA, 2012, CRUZ, 2012). Tal dificuldade está associada aos altos investimentos na atividade produtiva, especialmente na estrutura física. Esses obstáculos estão mais acentuados nesse contexto devido às características dessas famílias, que, de forma geral, produzem em pequena escala e desenvolvem a industrialização e também outras atividades, especialmente a agricultura, a pecuária e outros serviços. No Rio Grande do Sul, estima-se que existam cerca de 7.600 unidades produzindo e comercializando seus produtos de maneira informal (RIO GRANDE DO SUL, 2012).

Quando desenvolvidas pelos agricultores familiares, as atividades de processamento de alimentos adquirem complexidade e dinamismo específico. Nesse contexto, os agricultores e suas famílias executam (parcialmente ou totalmente) as ações desde a produção da matéria-prima até a comercialização dos alimentos. Outras características referem-se aos aspectos singulares na forma como estas famílias estão relacionadas com a agricultura, nas maneiras como elas viabilizam a produção e constroem relações com os mercados (AGNE, 2010).

Esse acúmulo de funções não está relacionado somente à heterogeneidade da agricultura familiar, mas também à própria diversidade social, econômica e cultural que caracteriza as atividades de processamento de alimentos. Ao considerar a história das famílias brasileiras nessas atividades, percebe-se que a atividade de processamento de alimentos é dependente, ainda, da forma como os agricultores familiares construíram e modificaram as suas técnicas produtivas.

Assim, essas atividades evoluíram ao longo do tempo. Os agricultores adotaram novas práticas e novos processos, influenciados por um conjunto de conhecimentos e saberes técnicos. Tal constatação direcionou a oportunidade de investigar sobre as trajetórias, compreendendo a forma como os atores adotam e modificam as práticas produtivas ao longo do tempo. Os estudos que se propõem a entender as atividades e as suas evoluções podem auxiliar na ampliação do 
conhecimento sobre as transformações ocorridas na agricultura, especialmente quando essas pesquisas estão relacionadas ao entendimento de mudanças no contexto da agricultura familiar no Brasil.

Nesse sentido, o presente artigo tem como objetivo apresentar uma proposta de uma tipologia para caracterizar as atividades de processamento de alimentos, utilizando como contexto empírico a realidade de quatro regiões gaúchas. Para tanto, está estruturado em cinco partes, a contar desta introdução e das considerações finais. Na próxima seção serão apresentados os principais conceitos utilizados no trabalho, e, especialmente, os fundamentos da abordagem evolucionária que guiaram o desenvolvimento deste trabalho. Na terceira seção será descrita a metodologia da pesquisa, com a contextualização do empírico. A quarta seção será destinada à apresentação dos resultados e análises, com o foco sobre a apresentação da tipologia, com a descrição sobre as trajetórias das famílias nas atividades de industrialização de alimentos.

\section{As atividades de processamento de alimentos no contexto da Agricultura Familiar}

$\mathrm{Na}$ literatura brasileira, é comum o uso de expressões, tais como "Agroindústrias rurais", "Agroindústrias caseiras", "Agroindústrias de pequeno porte" e "Agroindústrias rurais familiares" (GUIMARÃES; SILVEIRA, 2007, MIOR, 2007, AGNE, 2010, WESZ JÚNIOR, 2009, GAZOLLA, 2012). Um dos conceitos mais utilizados nos estudos sobre esse tema é apresentado por Mior (2007, p.10), que caracteriza as agroindústrias rurais familiares pelas atividades por meio das quais as famílias rurais "produzem, processam e/ou transformam parte de sua produção agrícola e/ou pecuária, visando, sobretudo, a produção de valor de troca que se realiza na comercialização".

Para o Ministério do Desenvolvimento Agrário, as agroindústrias rurais também podem beneficiar e/ou transformar produtos de origem agrosilvopastoril, aquícola e extrativista, incluindo o artesanato (BRASIL, 2004). A definição de Agroindústrias Rurais utilizada pelo Instituto Brasileiro de Geografia e Estatística IBGE considera que a produção da matéria-prima e o processamento podem ser realizados das seguintes formas: própria, terceirizada ou comunitária. A única ressalva é a destinação do produto final, que deverá ser realizada pelo produtor.

Considerando as motivações que conduzem as famílias a processarem produtos da agropecuária, pode-se destacar dois cenários. O primeiro está relacionado com a reprodução de práticas que já eram realizadas por gerações passadas, em que a família produtora é motivada a dar continuidade à atividade desenvolvida pelos pais e/ou avós (PETTAN, 2004, PEREIRA; NEVES, 2004). Nessa situação, as agroindústrias podem também ter origem na história e na cultura de imigrantes europeus que trouxeram ao Brasil um conjunto de técnicas para a fabricação desses produtos (PELEGRINI; VELA, 2005). Ou ainda, pela necessidade dos agricultores em prolongar a vida útil da produção agrícola perecível, oportunizando o armazenamento dos produtos que serviam, primeiramente, como fonte de alimentação para a família (BRITO, 2005; MIOR 2005).

O segundo está relacionado com a busca dos agricultores por outras atividades mais rentáveis, especialmente quando a família não está satisfeita com os ganhos financeiros obtidos com a produção e venda de produtos da agricultura 
e pecuária, especialmente grãos e tabaco (AGNE, 2010). Essas assertivas relacionam-se com o processo denominado "squeeze da agricultura", que pode ser compreendido pela forma como a modernização ocasionou o aumento do valor dos custos da produção, na proporção maior comparada aos valores obtidos com a venda dos produtos da agricultura e pecuária (PLOEG et al.,2000). Nessa situação pode-se destacar a influência de agentes de extensão rural, especialmente atores locais, engajados na proposição de atividades agroindustriais como alternativas de renda e uso de recursos públicos disponíveis (VIEIRA, 1997, AGNE, 2010). No entanto, apesar de um dos fatores motivacionais ser o de ordem econômica, é pertinente destacar que, em muitas situações, ele não está isolado de outros interesses das famílias, já que desenvolver a atividade pelo prazer, terapia e ocupação de mulheres e jovens é outra das razões que marcam a origem das "agroindústrias" (AGNE, 2010).

Sobre as características dessas atividades, segundo Polman et al.,2011, Oostindie et al.,2011 e Ploeg et al., 2002, estão sendo cada vez mais relacionadas aos mercados emergentes, onde a origem dos alimentos é conhecida pelos consumidores; os produtos possuem características específicas que conferem diferenciação e as formas de comercialização são particulares da organização dos grupos sociais envolvidos. No âmbito gaúcho, os mercados dos produtos industrializados pela agricultura familiar são caracterizados, essencialmente, pela proximidade entre agricultores e consumidores, pela rede de relações entre organizações sociais, pequenos e médios estabelecimentos comerciais (GAZOLLA, 2009).

\subsection{Entendendo trajetórias pelas ideias evolucionárias}

Compreender trajetórias significa relacionar não somente elementos do passado, mas também entender as formas como os agricultores direcionam suas atividades, fazendo uma imagem futura sobre elas (PLOEG, 2003).

Ao longo do tempo, as atividades de processamento de alimentos foram transformadas, seja pelos próprios agricultores seja por influências de agentes externos, governamentais e não governamentais. Compreender tais mudanças é pertinente, uma vez que permite identificar os rumos que essas atividades terão no futuro, especialmente no contexto da agricultura familiar.

Um dos principais autores que buscam relacionar: evolução, trajetórias e hábitos refere-se a Thorstein Veblen, precursor da Original Institutional Economy OIE. Embora o autor seja bastante utilizado para compreender a cultura do consumo e do lazer e as instituições, seu legado também traz contribuições para entender como os agricultores modificam as suas atividades, mediante a adoção de novas práticas e itinerários técnicos.

Veblen (1987) também auxiliou o entendimento sobre as atividades econômicas e sociais por meio de um processo histórico envolvendo elementos teóricos do Darwinismo Social. A epistemologiaevolucionária pode ser utilizada não somente para entender os fenômenos biológicos, mas, principalmente, para compreender as atividades humanas, que envolvem a linguagem, política, aprendizagem, ciência, ética, cultura, etc. (HODGSON, 2005).

O tempo é um elemento relevante na análise Vebleniana, já que ele é um fator explicativo, por exemplo, nos casos em que as famílias modificam os seus 
hábitos que estão enraizados e reproduzidos ao longo de gerações. No que diz respeito às mudanças técnicas e tecnológicas, tal análise considera que as ações realizadas no passado influenciam e restringem as opções e escolhas que serão realizadas no futuro, como menciona Dosi (1988, p.1130) "o que uma organizaçãoplaneja em termos de mudanças tecnológicas no futuro está restrita às ações tomadas no passado".

No contexto das atividades de processamento de alimentos na agricultura familiar, os processos pelos quais as famílias modificaram as suas práticas historicamente, constituem elementos explicativos das trajetórias. Porém, tais trajetórias não são constituídas por etapas, de forma linear. Pelo contrário, as transformações são como processos indeterminados, pois cada ator envolvido carrega um conjunto de conhecimentos, que são característicos da sua relação com a agricultura (MOORS et al., 2004). Durante o processo de transformação, novas situações emergem, podendo conduzir as mudanças para outras direções, inclusive há a possibilidade delas evoluírem para a promoção de efeitos negativos ao desenvolvimento rural (PLOEGet al., 2000). A possibilidade de um cenário desconhecido e incerto é uma outra característica que marca as contribuições evolucionárias de Veblen, o qual considera que o aspecto "blind drift" das trajetórias.

Nessa perspectiva, qualquer mudança deve ser interpretada como resultado de um processo que envolve escolhas dos indivíduos, que as executam segundo as suas reflexões em torno dos contextos sociais dos quais fazem parte. A adoção de uma nova técnica, prática, tecnologia e ações dependem da forma como as pessoas visualizam as oportunidades e as possibilidades, dentro das circunstâncias que permeiam as atividades que desenvolvem. Também incluem nas trajetórias evolucionárias: a experiência, os saberes e as maneiras como os indivíduos os transformam (HODGSON, 2004). Os indivíduos não reproduzem completamente um contexto social determinado. Pelo contrário, eles estão munidos de diferentes conhecimentos e capacidades, que conduzem à realização de diferentes escolhas. Uma das preocupações da análise evolucionária é justamente compreender a variabilidade, assim como investigar sobre os fatores e condicionantes da diversidade.

A análise sobre as trajetórias rompe, ainda, com a análise sobre as mudanças temporárias e estáticas, realizadas por um período relativamente "curto" de espaço de tempo. No caso específico das atividades de processamento de alimentos na agricultura familiar, algumas famílias estão constantemente modificando seus comportamentos de forma temporária, devido à ação fiscalizadora dos agentes responsáveis pela cobrança quanto ao cumprimento das normas sanitárias de produção, comercialização e consumo desses alimentos. Partindo da proposta analítica e evolucionária de Veblen (1987), este trabalho não considera tais mudanças, já que o foco da análise foi centrado na compreensão sobre a história e mudanças que foram cristalizadas no coditiano das famílias envolvidas nas atividades de processamento de alimentos. O víes epistemológico conduz ao mapeamento e seleção de mudanças que conduziram as famílias a cenários diferentes nesse contexto.

\section{Metodologia}


A pesquisa foi desenvolvida no período de agosto a novembro de 2012, com 64 famílias (agricultores familiares) que processam alimentos em três regiões distintas do Rio Grande do Sul, a saber: Hortênsias, Sul e Jacuí Centro, pertencentes aos Conselhos Regionais de Desenvolvimento - COREDEs, conforme as informações constantes na Figura 1 e a Tabela 1, apresentadas a seguir. Tais regiões foram escolhidas porque apresentam características diversas sobre as atividades de processamento de alimentos desenvolvidas pela agricultura familiar, especialmente sobre os aspectos históricos, sociais e econômicos.

Figura 1. Localização dos COREDEs (RS): regiões e municípios da pesquisa

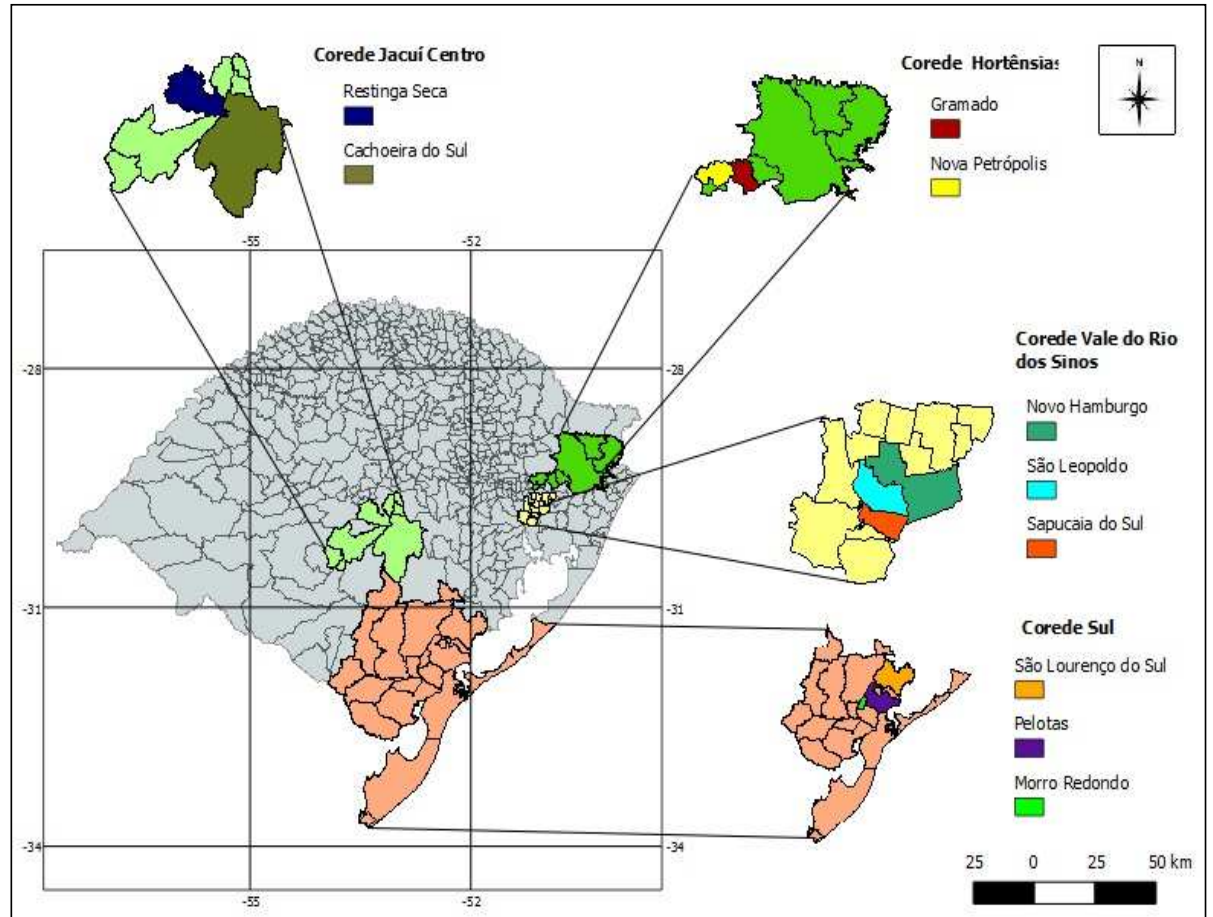

Fonte: Elaboração cartográfica: Márcio Zamboni Neske, com base IBGE. Mapa digital dos municípios brasileiros (2010).

Tabela 1. Regiões, municípios e número de famílias entrevistadas em cada localidade

\begin{tabular}{ccc}
\hline Corede & Município & $\begin{array}{c}\text { Número de famílias } \\
\text { entrevistadas }\end{array}$ \\
\hline Vale do Rio dos & Novo Hamburgo & 8 \\
Sinos & São Leopoldo & 2 \\
Hortênsias & Sapucaia do Sul & 5 \\
Sul & Nova Petrópolis & 6 \\
& Gramado & 9 \\
Jacuí Centro & São Lourenço do Sul & 10 \\
& Pelotas & 5 \\
& Morro Redondo & 3 \\
& Cachoeira do Sul & 9 \\
& Restinga Seca & 7 \\
\hline
\end{tabular}

Fonte: Elaborado pelos autores, informações da pesquisa (2012) 
Além dos estudos exploratórios nas regiões e localidades pesquisadas, foram utilizadas entrevistas testes, semiestruturadas e em profundidade, observações e diários de campo para coletar os dados.

As informações sobre as famílias foram obtidas por meio dos contatos com órgãos públicos e lideranças locais ligadas à agricultura familiar e ao desenvolvimento rural. Ademais, foram realizadas visitas às feiras de comercialização dos municípios e em organizações sociais, especialmente cooperativas e associações. As famílias foram selecionadas de forma dirigida, não aleatória, respeitando a captação da diversidade social. Não foi definido, a priori, o número de famílias que seriam entrevistadas. Em pesquisas qualitativas, o número de informantes depende da profundidade das respostas, qualidade, recorrência e divergência das informações.

Tendo em vista preservar a identidade dos entrevistados, cada família foi identificada com um número, de acordo com a ordem em que aconteciam as entrevistas. As famílias foram selecionadas mediante a adoção de critério de conveniência, que objetivou identificar o público-alvo que participaria da pesquisa, que deveria apresentar as seguintes características:a) o desenvolvimento de, no mínimo, um tipo de produto/alimento industrializado e b) a vinculação com a definição de agricultura familiar, ou seja, gestão das atividades de produção, processamento e comercialização coordenadas pela família.

Com o auxílio de um formulário semiestruturado, os pesquisadores entrevistaram os componentes que poderiam representar a família (unidade de análise), especificamente aqueles envolvidos nas atividades de processamento de alimentos. O formulário semiestruturado foi composto de três partes, a saber: (1) caracterização socioeconômica da família (2) perfil das famílias nas atividades de processamento, abrangendo dados estrutura física, trabalho e matéria-prima; e (3) trajetória das famílias nas atividades de processamento (início, as principais mudanças e os planos futuros);

Para a análise dos dados, foram utilizadas duas ferramentas qualitativas: a análise de conteúdo e a construção de tipologia. A análise de conteúdo é caracterizada, segundo Rey (2002, p.143), como "uma técnica que se apoia na codificação da informação em categorias para dar sentido ao material estudado". A análise de conteúdo utilizada neste trabalho foi caracterizada pelo uso da abordagem qualitativa. Com o uso dessa técnica, a principal ferramenta de análise é caracterizada pelo teor das mensagens, e não pelo contexto em que estas foram produzidas (GHIGLIONE; MATALON, 1997). Na forma qualitativa, essa técnica pressupõe o uso de alguns procedimentos metodológicos, que incluem tais etapas: categorização, inferência, descrição e interpretação. Dessa maneira, os procedimentos adotados neste trabalho foram desenvolvidos de acordo com as seguintes etapas:

A primeira etapa consistiu na organização das informações, por meio da leitura do material constante nos formulários e diários de campo. Tal leitura serviu como subsídio para selecionar e codificar os materiais empíricos. Após a realização dessa leitura, a etapa seguinte foi caracterizada pelo desenvolvimento de categorias, que funcionou como uma espécie de "fio condutor" para a elaboração da análise e redação. Como unidade de análise, optou-se pelo uso da unidade de registro, que correspondeu às frases geradas nas entrevistas. Após identificar cada 
segmento de respostas às respectivas categorias construídas, foram realizadas as análises e descrições dos resultados.

Outra ferramenta utilizada de forma conjunta à da análise de conteúdo foi caracterizada pela construção de tipologias, que teve o objetivo de diferenciar grupos de famílias, sintetizar a amostra estudada e explicar a diversidade de situações encontradas. Os estágios para a construção de tipologias consistiram em quatro fases distintas (KLUGE, 2000, p. 5): a) desenvolvimento de dimensões analíticas relevantes; b) agrupamento de casos e análise de regularidades empíricas; c) análise das relações significantes e construção dos tipos; e d) caracterização dos tipos construídos.

\section{As atividades de processamento de alimentos: a relação com a agricultura e a diversidade de produtos desenvolvidos}

No que diz respeito às informações históricas do Rio Grande do Sul, o início das atividades de processamento de alimentos ocorreu no século XIX, quando os primeiros imigrantes alemães estabeleceram-se na região metropolitana, especialmente em São Leopoldo. Esses imigrantes trouxeram técnicas de industrialização dos produtos da agricultura e da pecuária, as quais foram desenvolvidas, primeiramente, como um recurso para a conservação desses produtos a fim de que servissem como alimento para a família. Nas demais regiões, o processo de imigração também influenciou a adoção dessas técnicas. Nas cidades de Nova Petrópolis e Gramado, por exemplo, os imigrantes de origem italiana também fizeram parte desse cenário. Atualmente, por exemplo, algumas famílias ainda cultivam técnicas que herdaram de antepassados, especialmente na fabricação de alimentos tais como: massas caseiras, cucas, linguiças e vinhos.

Ao considerar as diferentes histórias das famílias nas atividades de processamento de alimentos, foi possível perceber que as mudanças estão atreladas às suas histórias de vida. Nessa história, estão incluídas as dinâmicas das suas relações sociais, seus recursos sociais e financeiros, as suas motivações para iniciar e/ou continuar processando alimentos, assim como a forma como eles imaginam/percebem/visualizam essa atividade para o futuro.

Compreender as trajetórias das famílias nas atividades de processamento de alimentos requer entender também as suas histórias na agricultura. Nessas histórias, incluem-se as formas como as famílias estão gerindo as suas atividades na agricultura, diferenciando e destinando alimentos e/ou produtos para comercialização, troca e/ou para fins de consumo. Além disso, o acúmulo de experiências nas atividades da agricultura contribui para que as famílias configurem e reconfigurem as formas de uso e gestão dos recursos sociais e físicos para processar alimentos.

Portanto, as atividades de processamento são dependentes de recursos que são "internos" e "externos" à propriedade rural e estão relacionadas com as formas como as famílias se organizam - de forma social e produtiva as suas atividades na agricultura e na pecuária.

As informações empíricas comprovam essa assertiva, pois, para 61 famílias, a relação com a agricultura teve início no período da infância, uma vez que os pais e/ou avós também eram agricultores. Nesses casos, os agricultores, quando crianças, já tinham contatos com os trabalhos e as rotinas da agricultura e pecuária 
e participavam das tarefas produtivas. Por meio dessas rotinas, pais e avós estimularam as crianças no desenvolvimento de noções básicas da agricultura e pecuária, que envolviam um conjunto de afazeres, tais como as que envolviam os cuidados com o plantio, crescimento e colheita das plantações, até o tratamento de animais. Esse acúmulo de conhecimentos influenciou nas histórias das famílias, especialmente nas trajetórias das atividades de processamento. Percebeu-se que, mesmo para aquelas famílias que haviam iniciado a atividade de processamento após a realização de cursos técnicos de capacitação (uma das características que define as famílias do Grupo: Trajetória II, que será apresentado a seguir), muitos conhecimentos e saberes da agricultura serviram como suporte para o desenvolvimento da agroindústria. Esses saberes contribuíram para que as famílias adquirissem segurança em iniciar tais atividades, já que as técnicas de plantio, manejo e cuidado com os animais constituem uma das primeiras etapas no processo de fabricação desses alimentos.

As informações atuais sobre as atividades produtivas desenvolvidas pelas famílias é um dos principais elementos que ajudam a explicar a relação entre agricultura, pecuária e o processamento de alimentos. As famílias diversificam as suas atividades produtivas, fato associado com a possibilidade de ampliação dos recursos de matéria-prima para fabricar os alimentos industrializados. Do total da amostra, aproximadamente $90 \%$ das famílias estão desenvolvendo entre 3 a 7 atividades diferentes, de agricultura e pecuária e apenas $10 \%$ dedicam-se a uma ou duas produções. Na diversidade, estão incluídas:

a) as frutas (produzidas por 60 das 64 famílias), que são utilizadas tanto para o consumo da família quanto como fonte de matéria-prima para 0 processamento;

b) as produções de origem animal (abelhas, galinhas, suínos, gado de corte e de leite), que são atividades de 57 famílias e cujos destinos são os mesmos que os da produção de frutas. Especificamente sobre o uso desses produtos para o processamento, destacam-se a produção de mel, frango caipira (inteiro e em corte), linguiça, queijos, iogurte e achocolatados;

c) a horticultura (legumes e verduras) destinados ao consumo da família e comercializados de forma in natura. Das 49 famílias produtoras, 10 utilizam produtos da horta para a fabricação de conservas e molhos de tomate, enquanto 11 comercializam os alimentos após o uso de técnicas de processamento mínimo. Por meio dessas técnicas, os legumes e verduras são descascados, cortados, lavados e, em alguns casos, embalados. Nessas produções incluem-se, especialmente, as mandiocas e o kit sopa (assim chamado pelos agricultores - que incluem um conjunto de legumes e verduras, usualmente utilizados para fazer sopa.

d) outros produtos, que são destinados à alimentação animal, comercialização e/ou consumo da família, tais como a banana, as flores, a produção florestal (acácia e eucalipto), o fumo e as pastagens (aveia e azevém) estas últimas utilizadas como fonte de alimentação dos animais (especialmente o gado).

A diversificação dos produtos da agricultura e pecuária, por sua vez, reflete na diversidade dos alimentos processados pelas famílias. De acordo com a Tabela 2, a seguir, é possível observar que o total de famílias produtoras (139) excede o número total de famílias entrevistadas (64). Essa assertiva pode ser explicada pelo 
fato de que $62,5 \%$ das famílias estão atuando em, no mínimo, dois setores diferentes. Os produtos "doces e geleias" destacam-se pelo maior número de famílias produtoras (31), seguido do setor de panificação e confeitaria (26), derivados do leite (22), embutidos e produtos de origem animal (17).

Do total da amostra, $37,5 \%$ das famílias estão se dedicando, exclusivamente, ao desenvolvimento de produtos referentes a uma matéria-prima específica, como é o caso, por exemplo, do setor de panificação e confeitaria, cujo ingrediente principal é a farinha de trigo. Porém, mesmo nessas situações, as famílias estão diversificando seus produtos, que variam em consistência, sabor, tamanho, tonalidade e quantidade de calorias.

Tabela 2. Produtos processados e número de famílias produtoras

\begin{tabular}{cc}
\hline Produtos & Número de famílias produtoras \\
\hline Doces e geleias & 31 \\
Panificação e confeitaria & 26 \\
Derivados do leite & 22 \\
Embutidos e produção de origem animal & 17 \\
Produtos minimamente processados & 11 \\
Conservas de legumes e molhos & 10 \\
Derivados da cana-de-açúcar & 10 \\
Bebidas (sucos, licores e vinhos) & 7 \\
Ervas, chás e medicamentos & 3 \\
Farinhas & 2 \\
Arroz beneficiado e embalado & 1 \\
\hline
\end{tabular}

Fonte: Informações da pesquisa (2012).

\section{Tipologia e evolução das famílias nas atividades de processamento de alimentos}

Considerando o conjunto de informações sobre as trajetórias das famílias nas atividades de processamento de alimentos, foi conveniente elaborar uma tipologia, que teve a finalidade de revelar a diversidade dos perfis das famílias nessas atividades (QUADRO 1). Tal tipologia foi elaborada tendo como base 5 critérios, que mesclam as características de quando as famílias iniciaram na atividade (origem do saber), as mudanças técnicas ao longo do tempo (modificações técnicas) e os aspectos atuais (objetivos, matéria-prima, etc). Serão destacados alguns elementos da história das famílias na atividade de processamento, especialmente no que se refere à evolução técnica. A evolução técnica, neste trabalho, corresponde às mudanças na organização da produção e no espaço físico utilizado pela família para processar alimentos.

Quadro 1. Critérios utilizados para o desenvolvimento da Tipologia das famílias nas atividades de processamento de alimentos, de acordo com as características iniciais, de evolução e atuais

\begin{tabular}{|c|l|}
\hline Aspectos & \multicolumn{1}{c|}{ Critérios } \\
\hline Iniciais e de mudanças & $\begin{array}{l}\text { 1) Origem do saber fazer (quando as famílias iniciaram a atividade de } \\
\text { processamento) e mudança nos conhecimentos técnicos produtivos }\end{array}$ \\
\hline
\end{tabular}




\begin{tabular}{|c|l|}
\hline $\begin{array}{c}\text { Evolução e de } \\
\text { mudanças }\end{array}$ & $\begin{array}{l}\text { 2) Evolução no perfil da estrutura física e no uso de equipamentos } \\
\text { e/ou uso de trabalho manual }\end{array}$ \\
\hline \multirow{4}{*}{ Atuais } & $\begin{array}{l}\text { 3) Localização e relação entre produção de refeições e processamento } \\
\text { de alimentos }\end{array}$ \\
\cline { 2 - 2 } & $\begin{array}{l}\text { 4) Relação entre matéria-prima e frequência do processamento de } \\
\text { alimentos }\end{array}$ \\
\hline & $\begin{array}{l}\text { 5) Diferença de objetivos dos agricultores na atividade de } \\
\text { processamento de alimentos }\end{array}$ \\
\hline
\end{tabular}

Fonte: Informações da pesquisa (2012) .

O primeiro critério selecionado é composto de informações tanto históricas como atuais. As características que compõem esse critério referem-se ao saber técnico que as famílias tinham quando iniciaram a atividade de processamento e alimentos e à evolução desses saberes (se estes foram modificados ao longo do tempo). Investigar sobre a origem dos saberes técnicos que as famílias tinham quando iniciaram essa atividade é um indicativo relevante para identificar mudanças, tanto produtivas quanto técnicas. Ademais, esse critério serviu para distinguir as famílias que iniciaram as atividades com o saber de seus antepassados das que tiveram influência de cursos técnicos para iniciar o processamento. Assim, tais características podem revelar a influência das ações de técnicos locais na promoção de novas "agroindústrias". Esses aspectos podem revelar, ainda, se há diferenças entre os grupos, especialmente sobre a relação entre saberes técnicos e acesso aos programas e políticas públicas. Partindo desse contexto, três situações foram encontradas, conforme informações sintetizadas na Figura 2, abaixo:

Figura 2. Identificação da origem do saber-fazer e evolução dos conhecimentos técnicos

(1) Identificação da origem do saber-fazer e evolução dos conhecimentos

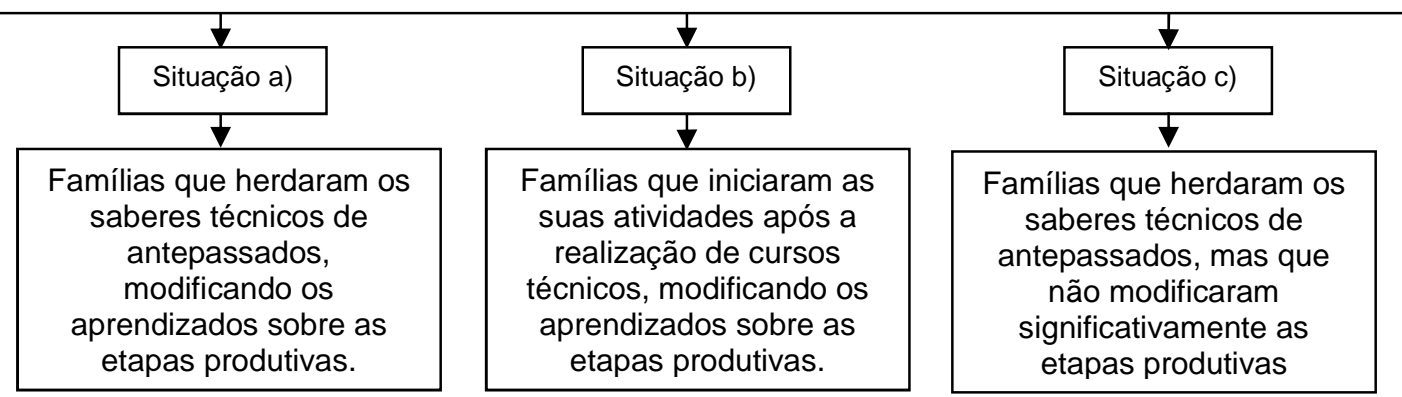

Fonte: Informações da pesquisa (2012). 
O segundo critério considerou um conjunto de aspectos relacionados à evolução do perfil da estrutura física - local onde são realizadas as atividades de processamento de alimentos, conforme as informações da Figura 3, a seguir. Esse critério considerou aspectos históricos sobre esse tipo de local, incluindo a evolução no uso de equipamentos e/ou na utilização de trabalho manual para desenvolver tais atividades.

Figura 3. Evolução do perfil da estrutura física e no uso de equipamentos e/ou o uso de trabalho manual nas atividades de processamento de alimentos.

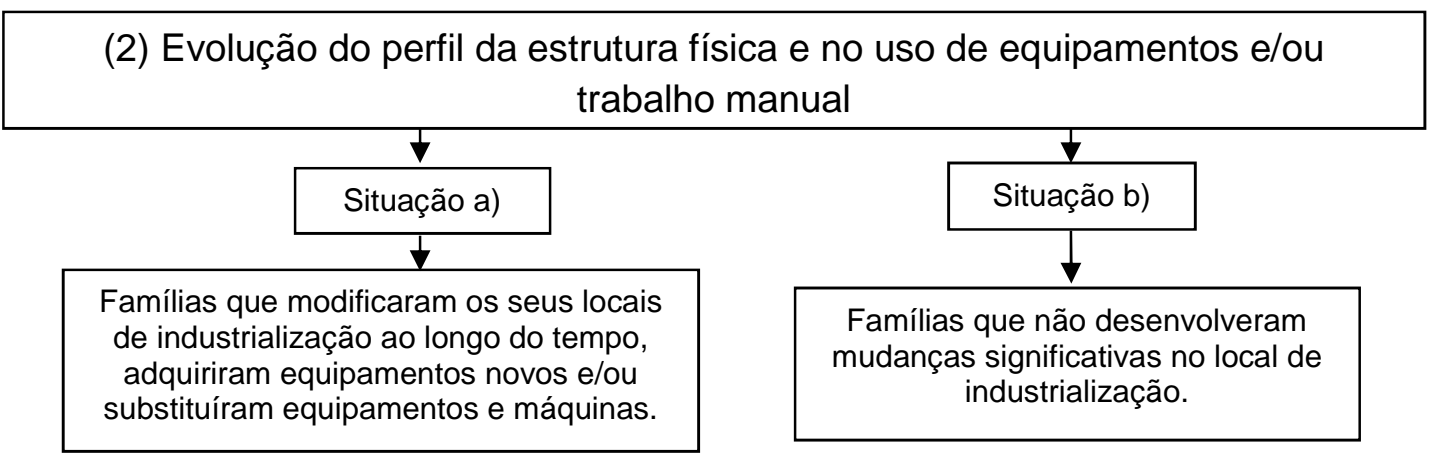

Fonte: Informações da pesquisa (2012).

O terceiro critério considerou as características do local onde os agricultores estão desenvolvendo as atividades de processamento de alimentos e produtos agropecuários, bem como a relação entre essas atividades e a produção de refeições para a família. A forma como algumas famílias integram ambos os ambientes (produção das refeições e processamento de alimentos) explica o modo como elas estão fabricando os produtos. No que se refere à organização do trabalho, por exemplo, as famílias que possuem uma estrutura em local separado da residência, em geral, podem desenvolver a atividade de processamento ao longo do dia. Além disso, nesses casos, o período de tempo de trabalho no processamento pode ser diferente, em virtude de todos os equipamentos e utensílios estarem organizados num local específico. O mesmo não acontece com as famílias que utilizam o ambiente da cozinha. Em geral, essas famílias destinam horários diferentes para o processamento de alimentos, já que precisam conciliar o mesmo espaço físico para a realização dessa atividade e para a da produção das refeições.

As características de localização ${ }^{1}$ da atividade de processamento também podem estar relacionadas com as diferenças nas trajetórias, especialmente quanto às mudanças técnicas. O espaço físico pode limitar a aquisição de equipamentos específicos para o processamento de alguns alimentos, especialmente quando as famílias aumentam a escala de produção de determinados setores, tais como a produção e armazenagem de bebidas (sucos, vinhos e cachaça). Esse critério, portanto, apesar de considerar elementos estáticos e informações atuais, é uma

\footnotetext{
${ }^{1}$ A localização das instalações das agroindústrias foi um dos critérios adotados por Guimarães e Silveira (2007) para a construção de uma tipologia, ao considerá-las como "estratégias de agregação de valor aos produtos oriundos do trabalho familiar" (p.7).
} 
informação que está relacionada com o critério anterior, que enfatizou aspectos sobre a evolução tanto da estrutura física quanto no uso de equipamentos.

Figura 4. Local onde acontece o processamento de alimentos e a relação entre essa atividade e a da produção de refeições familiares

(3) Localização e relação entre refeições familiares e atividade de industrialização
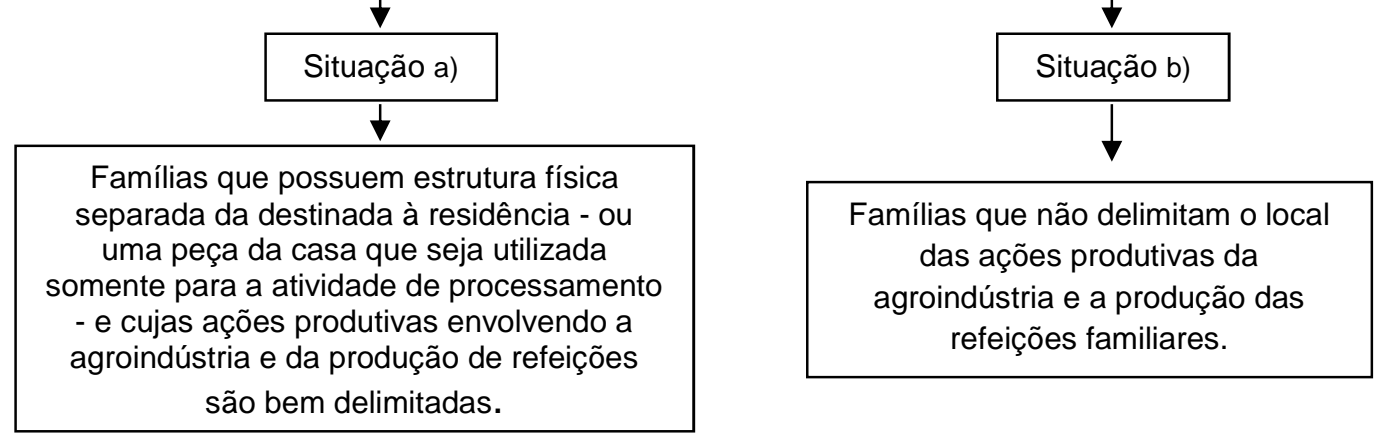

Fonte: Informações da pesquisa (2012).

O quarto critério revela a frequência com que as famílias estão produzindo os alimentos e os aspectos sobre a origem da matéria-prima que os agricultores utilizam para o processamento. Sobre isso, é pertinente considerar que há diferenças entre as famílias no que se refere à origem dos recursos de matériaprima. Há um grupo que utiliza somente produtos agropecuários excedentes da alimentação familiar e da comercialização, na forma in natura. Nesse caso, a atividade de processamento de alimentos não ocupa uma função prioritária na propriedade familiar. Esse grupo de famílias não deve ser analisado da mesma forma que o grupo de agricultores que está adquirindo, por meio de terceiros, recursos de matéria-prima ao longo de todo o ano. A pertinência em considerar essas diferenças justifica-se pela relevância em conhecer se esses diferentes perfis têm implicações sobre o acesso das famílias aos programas e políticas públicas, por exemplo. Essa assertiva relaciona-se com os argumentos de Wesz Júnior (2009, p.24), quando este afirma que, na região de Cerro Largo, Rio Grande do Sul, "os produtores escolhem pelo acesso aos programas a partir do papel que a agroindústria assume dentro do estabelecimento e de sua significância frente às demais ocupações desenvolvidas por eles".

Esses elementos podem ter influência na organização do conjunto de atividades na propriedade rural, no uso dos demais recursos produtivos, especialmente disponibilidade e alocação de trabalho (mão de obra). Em outras palavras, quando as famílias possuem o foco na agricultura e pecuária, a mão de obra ocupada pode estar mais concentrada nessas atividades. Outra questão refere-se à mão de obra familiar, que pode limitar o aumento de escala de produção e influenciar nos planos futuros da família para essa atividade. Consequentemente, essa limitação pode influenciar nas escolhas das famílias nessa atividade, como as decisões de processar alimentos somente a partir do uso do excedente da matéria-prima da agricultura e pecuária, por exemplo.

Assim, as escolhas que as famílias fazem ao longo das suas trajetórias nas atividades de processamento de alimentos não são somente elementos que podem explicar situações passadas, mas também trajetórias futuras. Por exemplo, algumas 
famílias podem ter iniciado as atividades de processamento utilizando somente matéria-prima excedente $e$, atualmente, podem estar mobilizando recursos externos para viabilizar essa produção (ou vice-versa). A síntese dessas informações pode ser observada na Figura 5, a seguir:

Figura 5. Diferença de objetivos das famílias nas atividades de processamento de alimentos

(4) Relação entre matéria-prima e frequência do processamento de alimentos

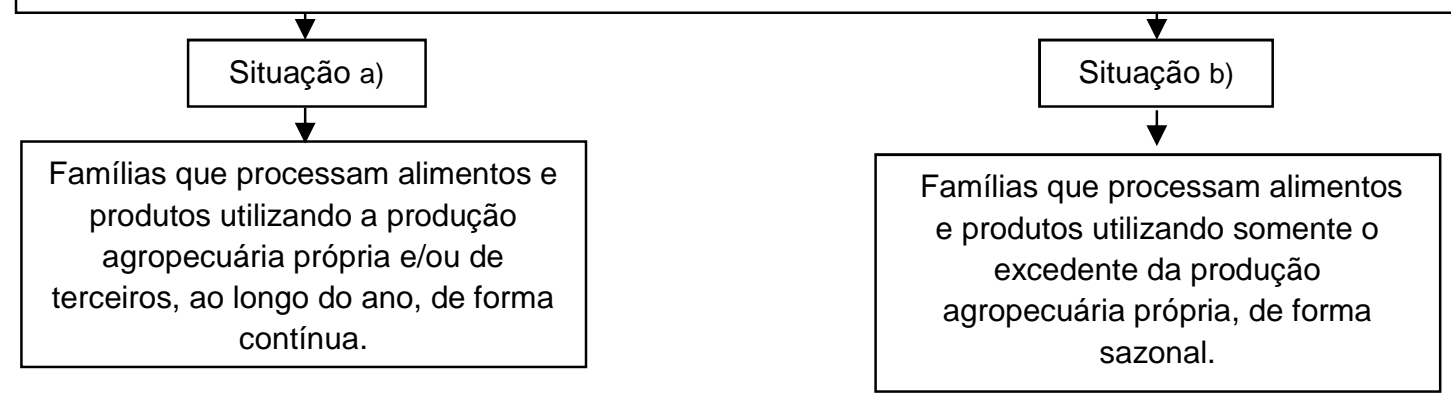

Fonte: Informações da pesquisa (2012).

O quinto e último critério adotado correspondeu às informações sobre as diferenças de objetivos das famílias no que se refere às atividades de processamento de alimentos e produtos de origem agropecuária (Figura 6). Essa diferença de objetivos expressa as diversas finalidades com que essa atividade é percebida pelo grupo familiar. Sobre isso, quatro situações foram encontradas: a) a primeira situação refere-se às famílias cujo objetivo principal dessa atividade é gerar renda. Nesses casos, a atividade de processamento de alimentos é uma das principais ocupações da família, que depende dessas funções para sustentar economicamente o grupo familiar;

b) a segunda situação corresponde às famílias que objetivam gerar renda e diversificar o portfólio de produtos e/ou de renda ou somente diversificar o portfólio de produtos e/ou de renda. Nesses casos, as famílias percebem essa atividade como alternativa de renda, já que elas desenvolvem outras atividades, como a agricultura e/ou pecuária. Dessa maneira, o processamento de alimentos é percebido como uma possibilidade de diversificar o portfólio de atividades e/ou de renda;

c) na terceira situação, as principais finalidades das famílias são diversificar o portfólio de produtos e/ou de renda e agregar valor, ou apenas agregar valor. Nesses casos, as famílias percebem a atividade como uma alternativa de renda, assim como na situação anterior. A diferença é a inclusão da função de agregar valor aos alimentos. A renda gerada por meio da venda dos alimentos processados é complementar. Portanto, agregar valor à matéria-prima da agricultura e pecuária e/ou diversificar as fontes de renda são as principais prioridades;

d) na quarta situação, os objetivos principais das famílias são conservar os alimentos, disponibilizá-los para a alimentação familiar e agregar valor à produção excedente. Algumas famílias, por exemplo, percebem a atividade de processamento de alimentos como uma técnica para conservar os produtos excedentes da agricultura e da pecuária. Os alimentos gerados podem ser 
utilizados tanto para a alimentação familiar como para atender aos pedidos de consumidores diretos. Essas finalidades são diferentes, por exemplo, dos objetivos das famílias que desenvolvem a atividade de processamento de alimentos com o objetivo principal de gerar renda (Situação a).

Figura 6. Diferença de objetivos das famílias nas atividades de processamento de alimentos

(5) Diferença de objetivos que as famílias possuem na atividade de industrialização

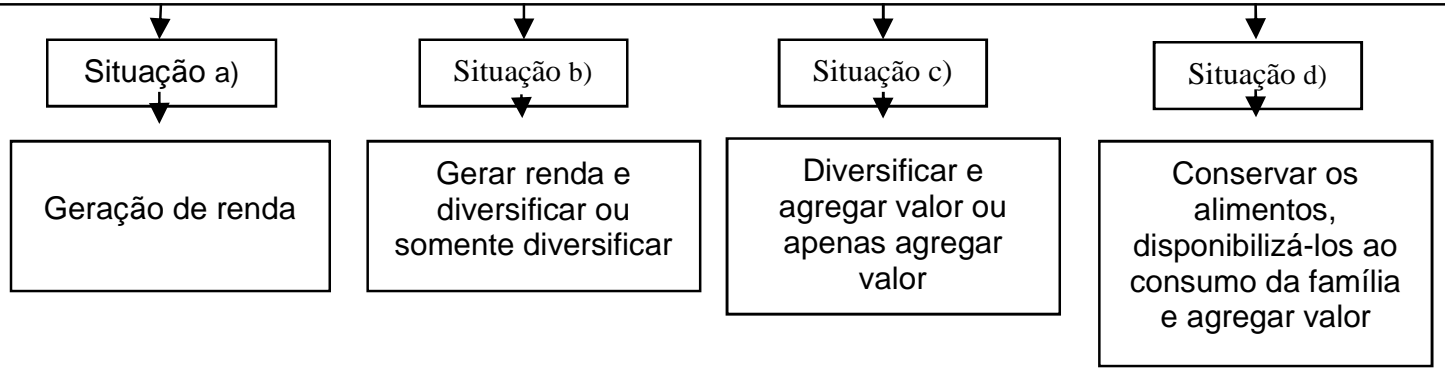

Fonte: Informações da pesquisa (2012).

Seguindo tais critérios, foi possível dividir o total da amostra (64 famílias) em quatro grupos diferentes, os quais foram denominados: Trajetória I, Trajetória II, Trajetória III e Trajetória IV. A seguir, serão apresentadas as particularidades que definem os grupos:

Trajetória I - Saberes antepassados, mudanças técnicas, espaço físico delimitado, produção contínua e objetivo: gerar renda

As famílias desse grupo possuem as suas trajetórias na atividade de processamento de alimentos relacionadas à história familiar, já que elas herdaram os conhecimentos técnicos dos pais e/ou avós. Esses conhecimentos referem-se às noções sobre as etapas produtivas e sobre os modos de fabricação dos produtos. Ao longo do tempo, as famílias foram aperfeiçoando esse conhecimento técnico, por meio da realização de cursos de capacitação na área produtiva e sanitária, mediante interação com agentes técnicos e de extensão rural e/ou por meio de interações com outros produtores que estão trabalhando no mesmo segmento produtivo.

A história da família 60 é um exemplo marcante da forma como a atividade de processamento de alimentos evoluiu nesse grupo. A produção de cachaça e vinhos é uma atividade tradicional da família, que teve início quando os avôs produziam essas bebidas para o consumo próprio. Com o passar dos anos, o filho ampliou a atividade, passando a vender os produtos para os vizinhos. A produção começou a diversificar a partir da construção de contatos do agricultor com agentes técnicos e fornecedores. Esses contatos contribuíram para a família desenvolver diferentes tipos de vinhos e licores. Por meio da utilização dos próprios recursos financeiros, a família adquiriu os equipamentos e construiu uma estrutura física para produção e armazenagem das bebidas. Apesar do tempo em que a família está envolvida nessa atividade (20 anos), o registro sanitário para a 
produção foi obtido somente há 3 anos. Após a ocorrência de denúncias, os órgãos locais exigiram uma série de mudanças na organização produtiva e na apresentação dos produtos. Dentre tais mudanças, verificou-se a exigência do uso de conservantes químicos nos vinhos. Utilizando a noção de evolução vebleniana, pode-se afirmar que os saberes herdados de antepassados foram transformados ao longo do tempo.

As famílias que pertencem a esse grupo também fizeram mudanças nos locais de processamento (estrutura física), que incluem a aquisição de equipamentos e/ou substituição de equipamentos e máquinas. Em alguns casos houve a construção de um espaço físico novo, enquanto, em outros, ocorreu a adaptação de estrutura física já existente (peça da casa, garagem). No caso da família 42, por exemplo, houve a transformação do local físico que ela utilizava para secar o fumo. Atualmente, essa mesma estrutura, reformada, é o local de processamento dos alimentos:

[...] a gente fazia na cozinha da residência. Mas era ruim, tinha refeição. Então, adaptamos a estrutura do secador de fumo, onde era o forno de fumo. Colocamos piso, arrumamos (Família 42).

Essa evolução técnica também incluiu a aquisição e/ou adaptação de equipamentos tendo em vista diminuir o trabalho despendido na produção. Em alguns casos, por exemplo, as famílias substituíram o maquinário antigo pelo maquinário novo. Essa tecnificação acarretou mudanças no uso da mão de obra familiar. A execução dos serviços da "agroindústria", antes realizado de forma manual, cedeu lugar à força de trabalho das máquinas, que minimizou os serviços e o tempo despendido na produção. Essa situação pode ser observada com clareza no depoimento da família três:

[...] antes a gente fazia no galpão, agora é numa estrutura própria. Hoje é um menor tempo dedicado à agroindústria. São só dois meio-dias por semana para a agroindústria. Os equipamentos deixam mais prático para trabalhar, diminui o tempo que eu gastava na agroindústria. Só os guris ou eu sozinho já consigo produzir. (Família 3).

Atualmente, as famílias desse grupo processam alimentos e produtos por meio do uso da produção agropecuária própria e/ou de terceiros, ao longo de todo o ano, sem interrupções. A razão dessa não interrupção está relacionada com o atendimento aos mercados, já que as vendas acontecem durante todos os meses do ano. Além disso, essas famílias estão mantendo ou se especializando no desenvolvimento de produtos agrícolas e pecuários, que servem como fonte de matéria-prima para realizar o processamento. Quando a fonte de matéria-prima própria não é suficiente, a família obtém os insumos necessários à produção, através de terceiros, com outros agricultores e/ou o comércio local/regional. Dessa forma, o desenvolvimento de produtos na agroindústria não é exclusivamente dependente da produção agropecuária própria. Nesses casos, a estrutura física é separada da residência ou situada em uma peça da casa, que é utilizada somente para essa atividade. Assim, as ações produtivas (refeições da família e processamento de alimentos) estão bem delimitadas. 
O principal objetivo atual dessas famílias na atividade de processamento de alimentos é gerar renda. O foco na geração de renda é justificado na medida em que os investimentos que as famílias desenvolveram nessa atividade (estrutura física e equipamentos) precisam ser viabilizados economicamente.

Trajetória II - Saberes cursos técnicos, mudanças técnicas, espaço físico delimitado, produção contínua e objetivos: gerar renda e/ou diversificar

Assim como as famílias que compõem a Trajetória I, os agricultores desse grupo têm as mesmas características, considerando os critérios 2, 3 e 4. Portanto, as famílias desse grupo não só realizaram mudanças no local de processamento, como também adquiriram máquinas e equipamentos específicos para essa atividade. O espaço físico é delimitado, e a produção é desenvolvida ao longo de todo o ano. Os únicos critérios que diferenciam esse grupo em comparação com as famílias da Trajetória I são a identificação da origem do saber fazer e os objetivos atuais das famílias na atividade de processamento de alimentos.

Ao contrário do grupo anterior, as famílias pertencentes a esse grupo iniciaram as suas atividades após a realização de cursos técnicos, aperfeiçoando, ao longo da trajetória, os aprendizados sobre as etapas produtivas. A herança, nessas situações, não possui relação com os saberes familiares, mas, sim, com o conhecimento que as famílias adquiriram nos cursos técnicos de capacitação, oferecidos pelos agentes técnicos e de extensão rural, da localidade e da região. Esses cursos tiveram como objetivo fornecer aos agricultores do município e da região noções práticas de processamento de alimentos, incluindo técnicas básicas de higiene e sanidade. Em algumas localidades, a realização desses cursos estava atrelada ao processo de incentivo à industrialização no meio rural, iniciativas que contavam com o apoio dos agentes ligados aos governos locais e aos órgãos de extensão rural locais, como pode ser percebido no depoimento da Família 13:

[...] começamos com a rota turística, e isso foi preparado pela Emater. O pessoal começou a produzir depois disso. Teve vários cursos, de cucas, de folheados, de compotas, de corte e costura, de higienização, de biscoitos (Família 13).

Nessas situações, a obtenção dos conhecimentos nesses cursos (que serviram como suporte para as famílias iniciarem as atividades de processamento) não significa que as famílias não tenham realizado mudanças ao longo da trajetória da agroindústria. Pelo contrário, as famílias aperfeiçoaram e modificaram suas produções por meio da realização de novos cursos técnicos e trocando experiências com outros agricultores. A diferença, nesse caso, refere-se à característica da trajetória dessas famílias, em que não há relação entre as noções básicas de fabricação e os saberes familiares. Um exemplo que retrata essa trajetória é o caso da Família 37, que produzia somente arroz orgânico até o ano de 2007. O início da produção da farinha de arroz foi desenvolvido após os pedidos dos consumidores locais, porém o agricultor não tinha conhecimentos sobre o processo de moagem dos grãos. Após participar de cursos de capacitação, a família iniciou a produção, construindo também uma estrutura física específica (com equipamentos e máquinas) para a produção de farinha de arroz. Segundo 
relatos da família, desde o ano de 2007, a produção está aumentando, devido ao aumento da demanda desse produto no município e região.

No que se refere aos principais objetivos atuais desse grupo de famílias, têm-se duas situações: a) a primeira situação refere-se às famílias que têm a finalidade tanto de gerar renda quanto de diversificar o portfólio de produtos; b) na segunda situação, as famílias objetivam somente diversificar.

$\mathrm{Na}$ situação da diversificação, a atividade de processamento de alimentos ainda não é o principal foco produtivo das famílias, já que ela apresenta o mesmo "destaque" que as demais atividades desenvolvidas na propriedade rural. Assim, a atividade de processamento de alimentos é percebida como uma oportunidade de diversificação e de renda. No entanto, já na situação de gerar renda e diversificar, pode-se perceber, em algumas famílias, uma tendência de foco nas atividades de processamento de alimentos. Por exemplo, se essa tendência se confirmar, no futuro, essas famílias modificarão seus objetivos nessa atividade: de geração de renda e diversificação optarão pela finalidade exclusiva de gerar renda.

Trajetória III - Saberes antepassados, sem mudanças técnicas significativas, espaço físico não delimitado, produção contínua e objetivos: diversificar e/ou agregar valor

As famílias desse grupo iniciaram da mesma forma que os agricultores que compõem o grupo Trajetória I, ou seja, por meio de conhecimentos herdados de antepassados. No entanto, esse grupo de famílias evoluiu de forma diferente da que foi percebida nos grupos anteriores, já que essas famílias não desenvolveram mudanças significativas, tanto nos saberes técnicos herdados quanto nos locais de processamento.

Dessa forma, o saber técnico e produtivo da agroindústria ainda está baseado no saber fazer da família, mesmo nos casos em que as famílias adotaram algumas mudanças. Assim, o contato com outros agentes (especialmente técnicos de extensão rural) proporcionou apenas a modificação de um processo, ingrediente ou método de produção, não tendo tido relação com um conjunto de mudanças mais amplas, como etapas e sequências produtivas, como pode ser observado a partir do depoimento da Família 35:

[...] a mudança que teve foi só que o SEBRAE deu ideia para eu fazer as cucas no mesmo padrão, em dois tamanhos: de 500 gramas e de 700 gramas (Família 35)

O local que as famílias utilizam para fabricar os produtos da "agroindústria" é o mesmo espaço físico de quando iniciaram a atividade. Nesse espaço físico (cozinha ou peça na residência), não há mudanças significativas. Apenas pequenas modificações nas suas características físicas (que incluem, em alguns casos, a colocação de azulejo, piso e modificações na organização dos móveis). Nos casos em que essas modificações aconteceram, elas não estão exclusivamente relacionadas ao ambiente da agroindústria, mas implicam em considerar que a residência (ambiente de convívio familiar) também foi modificada fisicamente. Os equipamentos são rudimentares, antigos e herdados de antepassados. 
Sobre as características atuais, esse grupo de famílias relaciona a preparação das refeições com a atividade de processamento de alimentos, não havendo uma delimitação de um espaço físico específico para desenvolver a atividade, ao contrário dos grupos anteriores. A atividade de processamento de alimentos, portanto, é realizada no ambiente da cozinha, que pode ser utilizado juntamente com outro local. As famílias utilizam outro espaço físico apenas para desenvolver atividades anteriores às de processamento, como abater animais, descascar frutas e legumes e armazenar os produtos.

Assim como nos grupos anteriores, a matéria-prima utilizada é própria e/ou terceirizada, e a atividade de processamento de alimentos é desenvolvida ao longo de todo o ano, sem interrupções. No que diz respeito aos objetivos das famílias, estes diferem quando comparados aos dos grupos anteriores. Nessa situação, as famílias percebem a atividade de processamento como uma oportunidade de diversificar e agregar valor à matéria-prima ou apenas agregar valor. Isso significa que esta atividade, da qual elas não dependem economicamente, representa uma renda a mais para as famílias. Portanto, ela é um incremento na renda familiar.

Trajetória IV - Saberes antepassados, sem mudanças técnicas significativas, espaço físico não delimitado, produção orientada pelo excedente e objetivos: conservar, consumir e agregar valor

As famílias desse grupo iniciaram a atividade de processamento de alimentos da mesma forma que os agricultores pertencentes aos grupos I e III. Dessa maneira, os saberes dos antepassados constituíram a base para as famílias iniciarem essa atividade. No que se refere aos aspectos de evolução técnica, as características desse grupo são semelhantes às do grupo anterior, ou seja, não havendo mudanças significativas, tanto nos saberes herdados de antepassados como no local físico de processamento.

Sobre as características atuais, as famílias desse grupo relacionam a produção de refeições e o processamento de alimentos (que é realizada na cozinha), assim como as famílias do grupo anterior. Todavia, um dos aspectos que diferencia esse grupo dos demais refere-se ao critério 4, que diz respeito ao uso da matéria-prima e à frequência do processamento de alimentos. Os agricultores desse grupo estão utilizando somente o excedente da produção agropecuária própria como matéria prima para fabricar esses alimentos. Tais atividades são desenvolvidas conforme a disponibilidade e/ou excedente de matéria-prima própria, tendo períodos em que não há produção. Num período de escassez dos produtos agropecuários (baixa produção), por exemplo, as prioridades são fornecer esses produtos para a alimentação da família ou comercializá-los de forma in natura.

Todas as características anteriormente mencionadas estão relacionadas aos principais objetivos atuais das famílias, que são conservar os alimentos, disponibilizá-los ao consumo familiar e agregar valor. Essa agregação de valor é desenvolvida nos períodos em que a família comercializa os alimentos processados. Essa realidade também pressupõe que o foco dos agricultores desse grupo não é a atividade de processamento de alimentos, embora ela possa contribuir para o consumo familiar e para a geração de renda em alguns períodos do ano. 
A família 55 é um exemplo ilustrativo dessa trajetória. A família produz melado, chimia (schmier) colonial e queijos há 33 anos. Os saberes dessa produção foram herdados dos pais e avós, que desenvolviam esses produtos para a venda e para o consumo familiar. O agricultor, que acompanhava o pai nas tarefas produtivas, especialmente no ambiente da feira do produtor, no município, decidiu dar continuidade às mesmas atividades que eram desenvolvidas pelos pais, especialmente a da produção de alimentos industrializados. Os equipamentos, herdados de antepassados, não foram substituídos. A família construiu uma estrutura física específica para a produção, porém, de forma simples (uso de tijolos sem cobertura). Atualmente, a produção é comercializada de forma direta aos consumidores da feira, em pequena escala. A principal atividade da família é a produção de grãos, especialmente a soja.

A Figura 7, a seguir, tem como finalidade apresentar as características desses quatro grupos de famílias de forma sintética, resgatando os aspectos mencionados anteriormente.

Figura 7. Características das trajetórias das famílias nas atividades de processamento de alimentos (Trajetórias I, II, III e IV)

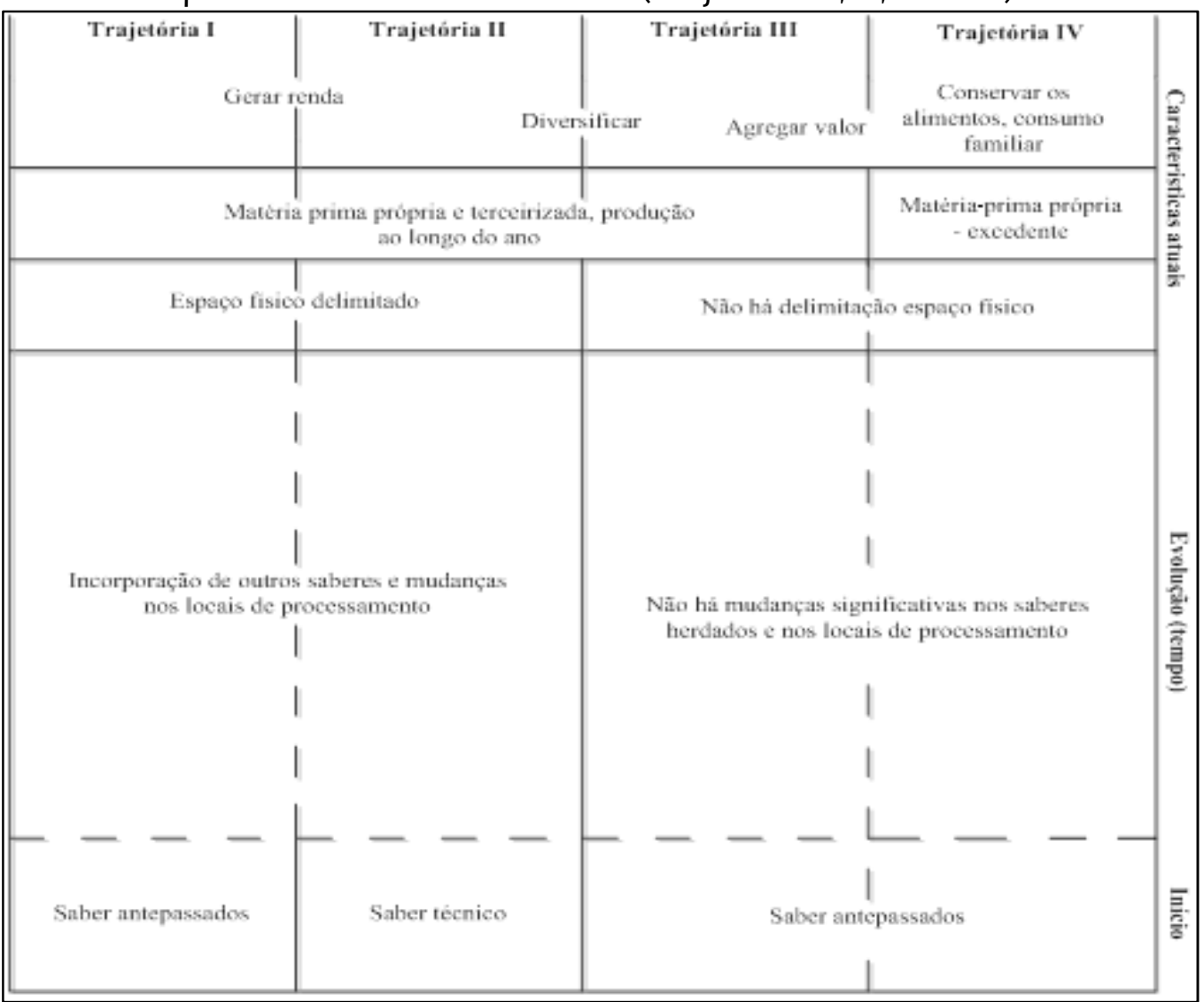

Fonte: Informações da pesquisa (2012).

De acordo com a tipologia apresentada anteriormente, 27 famílias estão compondo o grupo Trajetória I, representando 42,2\% da amostra, conforme dados do Gráfico 1, a seguir. Os demais grupos: II, III e IV apresentam, respectivamente, 13, 12 e 12 famílias. Todas as famílias da Trajetória I possuem registro e/ou o acompanhamento de um agente técnico para auxiliá-los nas 
práticas sanitárias nas atividades de processamento de alimentos. Essa situação é semelhante à das famílias da Trajetória II, em que 12 das 13 famílias possuem registro ou acompanhamento sanitário. No que se refere aos grupos de famílias das Trajetórias III e IV, a realidade é diferente. Quatro das 12 famílias da Trajetória III e uma família da Trajetória IV possuem registro e/ou acompanhamento de um técnico para desenvolver as suas atividades.

Gráfico 1. Tipologia das famílias nas atividades de processamento de alimentos: número total de famílias em cada grupo e número de famílias que possuem registro e/ou selo identificador da produção e/ou acompanhamento técnico

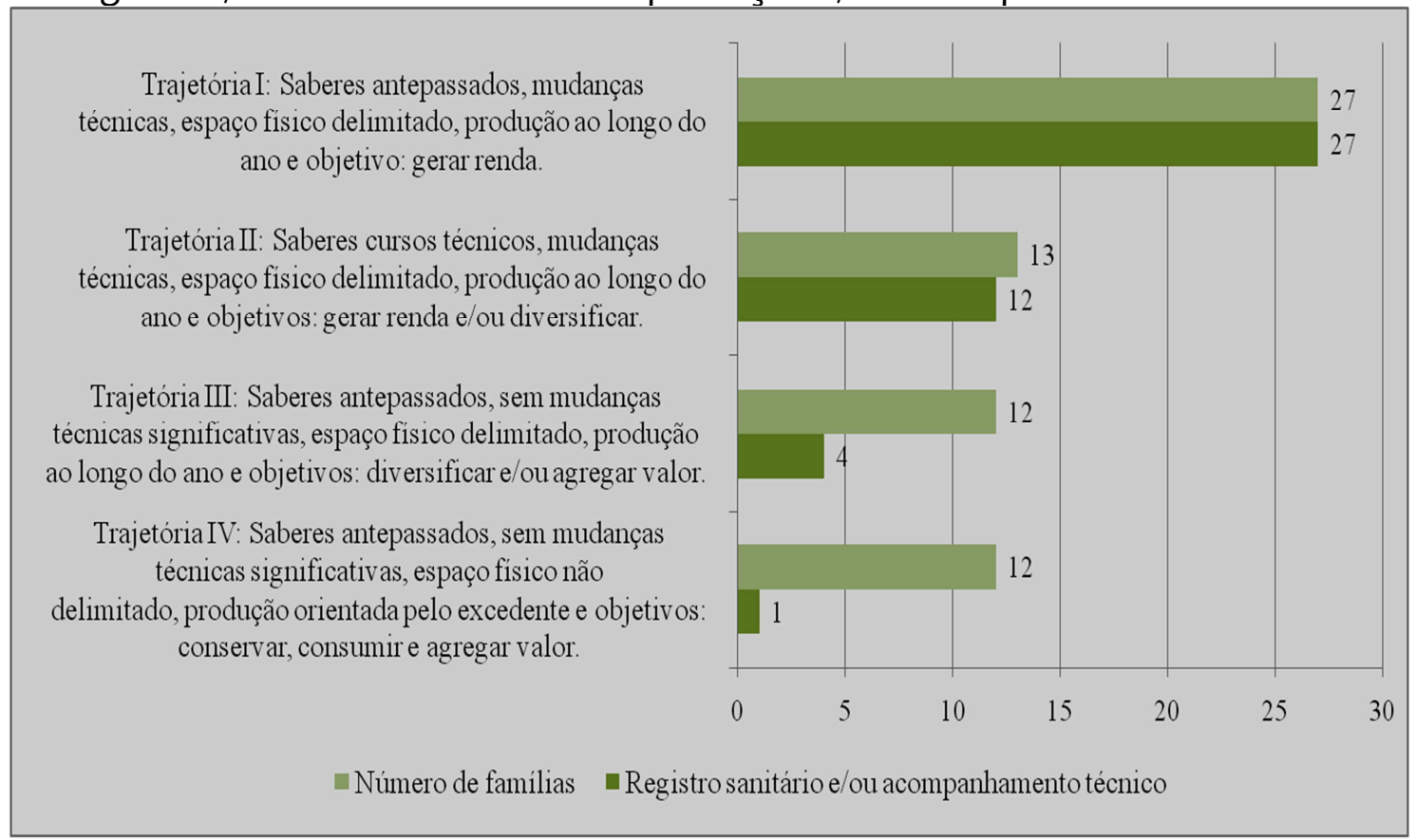

Fonte: Informações da pesquisa (2012).

\section{Considerações finais}

Os dados coletados nas regiões estudadas permitiram gerar uma riqueza informacional e analítica, que permitiram ampliar o conhecimento sobre 0 "universo" diverso que caracteriza as atividades de processamento de alimentos na agricultura familiar no Rio Grande do Sul.

Nesse conjunto de informações, pode-se perceber que há diferença entre os grupos, especialmente sobre a forma como iniciaram a atividade de processar alimentos e as transformações ocorridas ao longo das trajetórias.

O entendimento sobre como as famílias iniciam o processamento de alimentos perpassa pela compreensão de sua relação com a agricultura. Mesmo nas realidades em que as famílias começaram essa atividade após participar de cursos técnicos, elas somente puderam colocá-los em prática porque acumularam conhecimentos na agricultura com os antepassados. Na literatura sobre esse tema, a relação entre as atividades de processamento de alimentos e a agricultura não é facilmente percebida. Essa relação implica olhar as trajetórias e os saberes emergentes da interação das famílias nas tarefas domésticas e produtivas. 
A tipologia apresentada neste trabalho teve a pretensão de demonstrar a heterogeneidade pela qual tais atividades se apresentam no contexto da agricultura familiar. Também, os resultados poderão contribuir para ampliar o debate sobre os programas e políticas públicas nesse contexto, que demanda olhares, ações e intervenções diferenciadas.

As trajetórias das famílias nas atividades de processamento ainda desmitificaram as ideias de que os agricultores, especialmente os denominados "informais" não modificam seus saberes, suas técnicas, as formas como produzem e processam alimentos. A ideia da informalidade como sinônimo de "saber-fazer" ou "estagnação" do conhecimento produtivo já não é mais suficiente para entender a complexidade na forma como essa atividade está organizada na atualidade. Mesmo para os grupos de famílias que não empregaram mudanças técnicas significativas (componentes das Trajetórias III e IV), foi possível observar que houve obtenção de outros conhecimentos técnicos. Essas modificações podem acontecer em apenas uma etapa, produto ou processo produtivo. $E$, por essa razão, a identificação de mudanças pode não ser facilmente percebida, tornandose um desafio para uma agenda futura de pesquisas nessa temática.

\section{REFERÊNCIAS}

AGNE, C.L. Agroindústrias rurais familiares e a rede de relações sociais nos mercados de proximidade na região Corede Jacuí Centro/RS. 2010. 164f. Dissertação (Mestrado em Desenvolvimento Rural) Programa de Pós-Graduação em Desenvolvimento Rural Faculdade de Ciências Econômicas, Universidade Federal do Rio Grande do Sul, Porto Alegre, 2010.

BRASIL. Presidência da República. Casa Civil. Subchefia para Assuntos Jurídicos. Lei $n^{\circ}$ 11.326, de 24 de julho de 2006. Estabelece as diretrizes para a formulação da Política Nacional da Agricultura familiar e Empreendimentos Familiares Rurais. Brasília, DF, 24 jul. 2006.2 Disponível em: <http://www.planalto.gov.br/ccivil_03/_ato2004-2006/2006/lei/l11326.htm> Acesso em: 21 jan. 2012.

BRITO, C. de. A agroindústria artesanal e o programa fábrica do agricultor: uma Tentativa de Racionalizar as Atividades em uma Unidade De Produção Agrícola Familiar.2005.Dissertação (Mestrado em Sociologia) - Programa de Pós-Graduação em Sociologia, Universidade Federal do Paraná, Curitiba, 2005 Disponível em: <http://dspace.c3sl.ufpr.br/dspace/bitstream/1884/2611/1/DISSERTA\% C3\% 87 \% C3\% 830\% 20DE\% 20MESTRADO \% 20CELESTINO\% 20DE\% 20OLIVEIRA\% 20B RITO,\% 202005.pdf> Acesso em: 20 jun. 2007.

CRUZ, F. T. da. Produtores, consumidores e valorização de produtos tradicionais: um estudo sobre qualidade de alimentos a partir do caso do queijo serrano dos Campos de Cima da Serra - RS. 2012. 292f. Tese (Doutorado em Desenvolvimento Rural) - Programa de Pós-Graduação em Desenvolvimento Rural. Faculdade de Ciências Econômicas, Universidade Federal do Rio Grande do Sul, Porto Alegre, 2012 
DOSI, G. Sources, procedures and microeconomic effect of innovation. Journal of Economic Literature, Sidney,v.26, p.1120-1171, Sept.1988. Disponível em: <http://www.decon.unipd.it/info/sid/materiale8/Bel_Sources_Proced_Microec_Ef fect_Innov.pdf> Acesso em: 27 dez. 2010.

GAZOLLA, M. Conhecimentos, produção de novidades e ações institucionais: cadeias curtas das agroindústrias familiares. 2012. 292 f. Tese (Doutorado em Desenvolvimento Rural) - Programa de Pós-Graduação em Desenvolvimento Rural, Faculdade de Ciências Econômicas, Universidade Federal do Rio Grande do Sul, Porto Alegre, 2012.

GHIGLIONE, R.; MATALON, B. O inquérito: teoria e prática. Tradução Oeiras: Celta, 1997.

GUIMARAES, G. M.; SILVEIRA, P. R. C. da. Por trás da falsa homogeneidade do termo agroindústria familiar rural: indefinição conceitual e incoerências das políticas públicas.In: CONGRESSO BRASILEIRO DE SISTEMAS DE PRODUÇÃO, 7., 2007, Fortaleza. Anais... Fortaleza, 3 a 6 setembro de 2007. 1 CD-ROM. Disponível em: <http://www.cnpat.embrapa.br/sbsp/anais/Trab_Format_PDF/99.pdf>. Acesso em: 20 abr. 2010.

GUIMARÃES, G.M. Racionalidades identitárias na produção e comercialização de alimentos coloniais na Quarta Colônia, Rio Grande do Sul - RS. 2011. 220 f.Tese (Doutorado em Desenvolvimento Rural) - Programa de Pós-Graduação em Desenvolvimento Rural, Universidade Federal do Rio Grande do Sul, Porto Alegre, 2011.

HODGSON, M. G. Generalizing darwinism to social evolution: some early attempts. Journal of Economic Issues, Salisbery, vol. 34, n.4, p.899-914, Dec. 2005.

The evolution of institutional economics: agency, structure and darwinism in american institutionalism. New York: Routledge, 2004. 534 p.

KLUGE, S.Empirically grounded construction of types and typologies in qualitative social research. Forum: qualitative social research, Berlin, 2000. Disponível em: <http://www.qualitative-research.net/fqs/>Acesso em: 24 jan. 2013.

MIOR, L. C. Agricultura familiar, agroindústria e desenvolvimento territorial. In: COLÓQUIO INTERNACIONAL DE DESENVOLVIMENTO RURAL SUSTENTÁVEL, 1.,2007, Florianópolis. Anais... Florianópolis, 22 a 25 de agosto de 2007.1CDROM. Disponível em: <http://www.cidts.ufsc.br/articles/Artrigo_Coloquio_\%20Mior.pdf> Acesso em: 12 ago.2008.

Agricultores familiares, agroindústrias e redes de desenvolvimento rural. Chapecó: Argos, 2005. 
MOORS, E.H.M.; RIP, A.; WISKERKE, S.C. The dynamics of innovation: a multilevel co-evolucionary perspective. Seeds of Transition,Assen. Van Gorcum, p.31-49, 2004.

OOSTINDIE, H.A. et. al. The central role of nested markets in rural development in Europe. Rivista di Economia Agraria, Roma, v. 45, n.3, p. 191-224, 2011.

PELEGRINI, G.; VELA, H.Estudo das associações de agroindústrias familiares do município de Palmitinho - $R S$. In: CONGRESSO INTERNACIONAL DE DESENVOLVIMENTO RURAL E AGROINDÚSTRIA FAMILIAR, 1., 2005, São Luis Gonzaga. Anais... São Luiz Gonzaga, 8 a 11 de novembro de 2005. 1 CD-ROM.

PEREIRA, M. do C. S.; NEVES, R. I. S. Redes de agroindústria de pequeno porte: experiências de Santa Catarina. Florianópolis: BRDE, 2004. 154 p.

PETTAN, K. B. et al. Análise comparativa do desempenho da competitividade das agroindústrias familiares em rede e isoladas no oeste de Santa Catarina. In: CONGRESSO DA SOCIEDADE BRASILEIRA DE ECONOMIA E SOCIOLOGIA RURAL, 42., 2004, Cuiabá. Anais... Cuiabá, 25 a 28 de julho de 2004.Disponível em: <http://www.unb.br/ceam/neagri/PDF/flavio.pdf>Acesso em: 15 maio 2007.

PLOEG, J.D. van der. Past, present and future. In: . (Org). The virtual farmer. Assen: Van Gorcum, 2003. p.3-48.

et al. Rural Development: from practices and policies towards theory. Sociologia Ruralis, The Netherlands, v. 40, n. 4, Oct. 2000. Disponível em: <http://www.ufcg.edu.br/ cedrus/downloads/schneider/rural_evelopment.pdf > Acesso em: 10 jan. 2012

PLOEG, J.D. van der; LONG, N. Rural development: the state of art. In: PLOEG, J. D. van. der; LONG, N.; BANKS, J. (Org.). Living Countrysides, Netherlands: Elsevier, 2002. p.8-17.

POLMAN, N. et al. Nested markets with common pool resources in multifunctional agriculture. Rivista di Economia, Roma, v.45.n.3, p. 295 - 318, 2011.

REY, F.L.G. Pesquisa qualitativa em psicologia: caminhos e desafios. São Paulo: Pioneira, 2002.

RIO GRANDE DO SUL. Secretaria de Desenvolvimento Rural, Pesca e Cooperativismo. Departamento de Agroindústria familiar, Comercialização e Abastecimento. Programas e Projetos: Política Estadual de Agroindústria Familiar. Porto Alegre, 2012. Disponível em: <http://www.sdr.rs.gov.br/>. Acesso em: 2 fev. 2013.

VEBLEN, T. A teoria da Classe Ociosa. São Paulo: Nova Cultural, 1987.

WESZ JUNIOR, V.J. Políticas públicas de agroindustrialização na agricultura familiar: uma análise do Pronaf Agroindústria. In: CONGRESSO DA SOCIEDADE 
BRASILEIRA DE ECONOMIA ADMINISTRAÇÃO E SOCIOLOGIA RURAL, 47., 2009, Porto Alegre. Anais...Porto Alegre, 26 a 30 de julho de2009. 1 CD-ROM.

Submetido em 29/05/2016

Aprovado em 12/08/2016

\section{Sobre os Autores}

Chaiane Leal Agne

Doutora em Desenvolvimento Rural, Programa de Pós-Graduação em Desenvolvimento Rural (PGDR), Universidade Federal do Rio Grande do Sul (UFRGS). Professora Adjunta em Desenvolvimento Rural, Universidade Estadual do Rio Grande do Sul (UERGS). Rua Sete de Setembro, 943, Ap. 903. CEP. 96508 011. Bairro: Centro. Cachoeira do Sul, Rio Grande do Sul. Email: chaianeagne@gmail.com

\section{Paulo Dabdab Waquil}

Doutor em Economia Agrícola, Professor do Programa de Pós-graduação em Desenvolvimento Rural - PGDR/UFRGS. Endereço: Av. João Pessoa, 31; CEP 90040-000, Porto Alegre - RS, Brasil. E-mail: <waquil@ufrgs.br 